\title{
Reflections on the 4oth Anniversary of the Research Institute of Environmental Law, Wuhan University
}

\begin{abstract}
Ben BOER
Professor, Research Institute of Environmental Law, Wuhan University, Wuhan, China; Emeritus Professor, Sydney Law School, University of Sydney, Sydney, Australia; Co-editor-in-chief, Chinese Journal of Environmental Law ben.boer@sydney.edu.au
\end{abstract}

In the late 1970s, the People's Republic of China was emerging from the chaos of the Cultural Revolution, a decade-long period of political, social, economic, and cultural disruption during which the rule of law and legal institutions throughout China suffered greatly, including in the Universities. The reestablishment of Wuhan University School of Law in 1979 was led by Professor HAN Depei, who had already been a professor and Dean of the School of Law in the 1940s. As indicated by QIN Tianbao and HU Bin in the previous article, on his reappointment, Professor HAN perceived the need to promote the research and teaching of environmental Law, and, as a result, initiated the setting up of the Research Institute of Environmental Law (RIEL), of which he became the first director. ${ }^{1}$ From that time, Wuhan University has played a very significant role in the development of environmental law in China through its long-standing and rich research programme as well as its many years of postgraduate teaching.

With Professor HAN's idea for the establishment of the Research Institute, his involvement in the drafting of legislation and development of the field of environmental law in China, and his publication of many books and articles in the field, he inspired a generation of scholars from around China, as well as from abroad. The following is a brief personal reminiscence of my experience with HAN Depei and with the Institute.

I first visited Wuhan together with my University of Sydney colleagues Nicola FRANKLIN, Bernard DUNNE and Brian PRESTON (now Chief Judge of the Land and Environment Court of New South Wales). We were accompanied by

1 'Successive leaders: HAN Depei', RIEL Website <http://www.riel.whu.edu.cn/view/3.html>. 


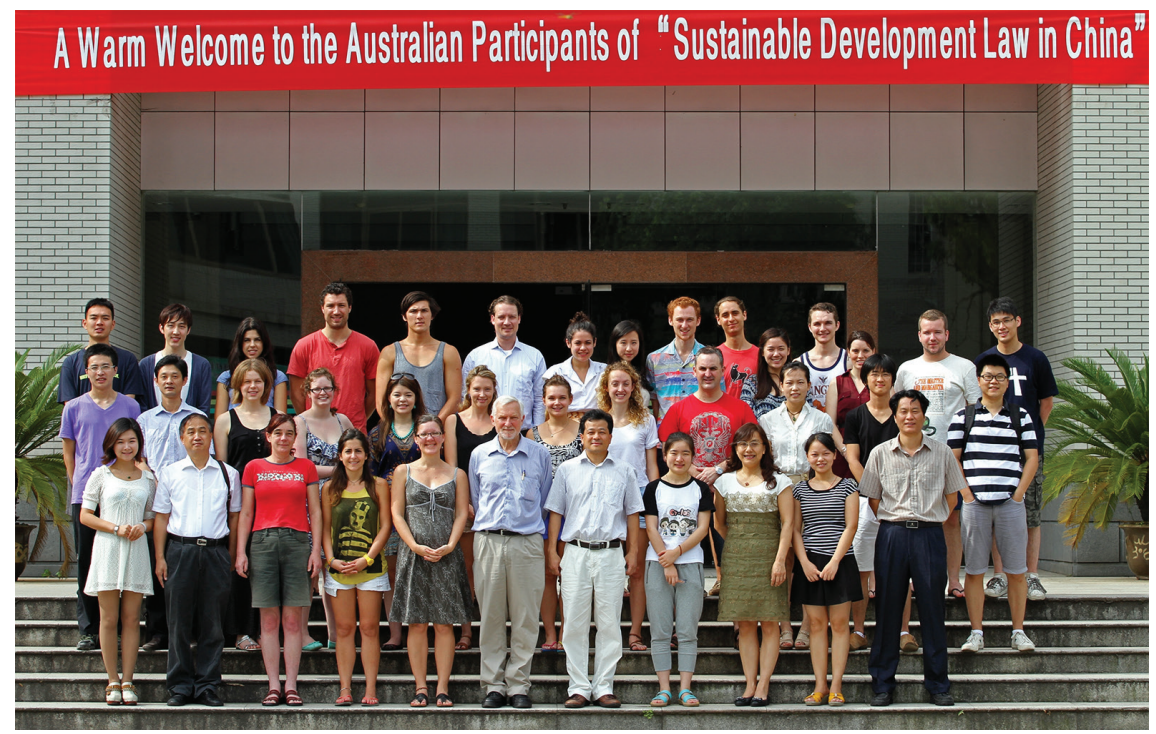

FIGURE 1 Students and staff of 'Sustainable Development Law in China' 2012

some 20 students from the University of Sydney. HAN Depei, together with his younger colleagues, CAI Shouqi and WANG Xi, made all of us feel very welcome. The program, 'Sustainable Development Law in China and Australia', continued off and on until the year 2012 and saw many dozens of Australian and other overseas students come to Wuhan, not only to learn about Chinese environmental law, but also to go on field trips such as the Three Gorges, to enjoy more of Chinese culture and cuisine.

Professor HAN passed away in his mid 9os, in 2009. In 2011, I took up an appointment as a Distinguished Professor of Wuhan University, under the Ministry of Education 1000 Global Talents Program. Whether by coincidence or by design, the then Director the Research Institute, Professor WANG Shuyi, allocated me to a wonderful office with a large desk, which, I was informed, was originally occupied by Professor HAN. Immediately outside and below that office, accompanied by a tree planted in his honour, sits the statue of Professor HAN, with a benign look on his face, and regularly, a bunch of fresh flowers in the crook of his arm, placed there by an admiring passer-by.

It transpired that in that office in 2016, Professor QIN Tianbao, now director of the Research Institute and Dr HU Bin, deputy director, planned with me to establish the first journal of environmental law in China, which Wuhan University agreed to generously support. Seven years later, with the assistance of the publishing team at Brill/Nijhoff, our previous managing editors Professor Benoit MAYER and Associate Professor Colin MACKIE, our current managing 
editor Professor Otto SPIJKERS and our small editorial team of Dr Rowena CANTLEY-SMITH, Dr DAI Liping and Dr Richard ZHANG Qing, we have completed five volumes of the Chinese Journal of Environmental Law. In 2021 our journal achieved recognition by two major international journal indexers, the Web of Science, and Scopus.

In 2018, with the financial assistance of the United Nations Environment Programme and support from several law Wuhan law firms, the assistance of the Wuhan Legal Aid Clinic and with the encouragement of the Law School and the University, we were able to establish the Environmental Law Clinic, of which Associate Professor LI Guangbing became the Director, with Associate Professor WU Zhiliang named as Deputy Director.

From 2017 to 2021, supported by a grant from the Chinese Ministry of Education, the Research Institute of Environmental Law undertook a collaborative research project on Ecological Globalization and International Environmental Law. A highlight of that project was the conduct of an international workshop focused on this field in October 2019, an output of which was a Special Issue of this Journal. ${ }^{2}$

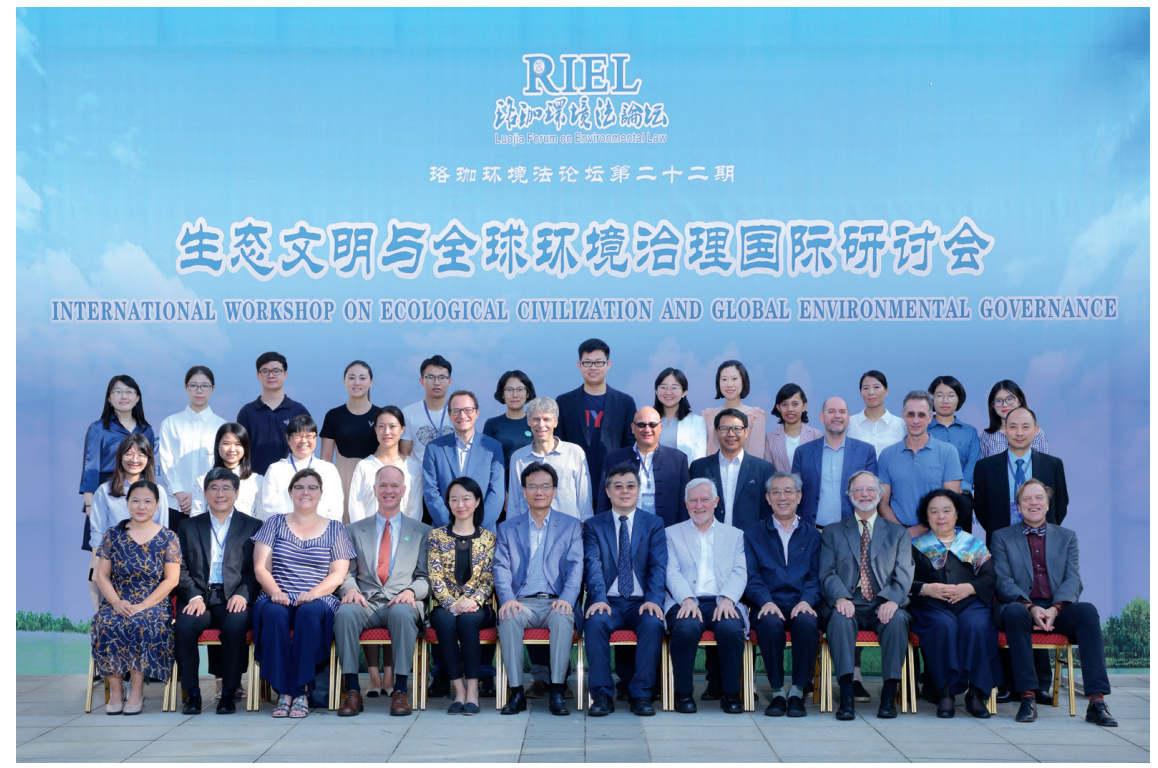

FIGURE 2 Participants at RIEL's International Workshop on Ecological Civilization and Global Environmental Governance, 22-24 October 2019

2 'Ecological Civilization and Environmental Governance' (2020) 4(2) Chinese Journal of Environmental Law 122-264. 
In the area of environmental law, lawyers obviously have a significant role to play, at government level in drafting and administering the laws, as judges in the courts enforcing the law, as lawyers in representing clients (whether they be private sector, government, or non-government organisations), to ensure that environmental law is properly and robustly implemented and enforced. However, it is professors who have perhaps the highest responsibility, both as teachers and as researchers, because the students of today will become the government administrators, the judges and practising lawyers of tomorrow. It is the responsibility of professors therefore to not only ensure that the law itself is learned and understood. We must encourage our students to uphold the very highest ethical standards regarding the environment, by specifically placing the conservation and protection of the environment above economic and political considerations. We also need to ensure that as far as possible, an interdisciplinary approach is taken in our teaching and research. The disciplines of political science, economics, sociology, psychology, the natural sciences and international relations are all relevant to this endeavour. Judging by the record of his service, his education in North America and China and his broad academic interests, there is no doubt that HAN Depei, would have agreed with this approach.

By remembering Professor HAN Depei here, on the 4oth anniversary of the Institute, I want to underline the point that we all have the potential to make the same difference as he made during his long life. Having seen the development of the Institute over a quarter of a century from my first visit, I am confident that its hundreds of students are making a substantive difference to the quality of the environment both nationally and internationally through the mechanisms of environmental law, and that they, and their successors, will continue to do so for at least another 40 years, inspired by the work and example of its professors, and in particular the shining example of Professor HAN Depei.

It is my privilege to be part of the history of the Research Institute of Environmental Law, to be provided with the many opportunities that I have been given, to learn so much more about Chinese people and culture. I wish the Institute, its professors and scholars, and its students, the very best for the future. 